\title{
PReS-FINAL-2118: Painless contractures of fingers in a female child
}

\author{
A Gagro", AM Kapović, M Žutelija Fattorini, G Krakar, G Roić \\ From 20th Pediatric Rheumatology European Society (PReS) Congress \\ Ljubljana, Slovenia. 25-29 September 2013
}

\section{Introduction}

We describe a 6-year-old girl with a sudden onset of symmetrical and painless joint contractures of fingers on both hands, without obvious skin changes, following an exercise (roller skating) while she was holding hard for a wall rail. She was first presented to the Department of Neuropaediatrics with the suspected diagnosis of a neuromuscular disorder. During initial patient consultations that included an rheumatologist a marked blood eosinophilia was found. No telangiectasia, calcinosis, megacapillary, sclerodactyly, or mucosal involvements were present. The patient showed neither Raynaud phenomenon nor digital ulceration.

\section{Objectives}

To describe an unusual presentation of eosinophilic fasciitis in childhood and clinical, laboratory and radiology findings that lead to the diagnosis.

\section{Methods}

Clinical, laboratory and radiologic examination were undertaken prior to a full thickness biopsy.

\section{Results}

In addition to eosinophilia of $23 \%$ absolute value (normal value up to $5 \%$; absolute number $2560 / \mathrm{microL}$ ), laboratory investigations showed an elevated erythrocyte sedimentation rate of $29 \mathrm{~mm}$ (normal value 6-20), normal C-reactive protein (CRP) and creatinine kinase (CK) levels, an increase of immunoglobulin G (to 17,6 g/L (normal range up to $14 \mathrm{~g} / \mathrm{L}$ ) and increased eosinophilic cationic protein of $100 \mu \mathrm{L} / \mathrm{L}$ (normal range up to $20 \mu \mathrm{L} / \mathrm{L}$ ). Immunological results were negative for scleroderma-specific autoantibodies. No sign of Borrelia burgdorferi infection was detected in serum. Muscle ultrasound and magnetic resonance imaging (MRI) of her right hand revealed thickened fascia and no joint involvement. A full thickness biopsy confirmed the diagnosis of eosinophilic fasciitis. Oral corticosteroid therapy was initiated without side effects.

\section{Conclusion}

In most patients with eosinophilic fasciitis, the presenting symptoms are cutaneous with pitting edema, peau d'orange skin, and indurations mainly affecting the hands and feet sparing acral regions. To the best of our knowledge, the unusual presentation of painless contractures without involvement of the skin as seen in our patient was previously described in two children only. MRI was useful as a diagnostic tool to demonstrate that contractures in our patient were due to a fasciitis and not to joint involvement.

\section{Disclosure of interest}

None declared.

Published: 5 December 2013

doi:10.1186/1546-0096-11-S2-P130

Cite this article as: Gagro et al:: PReS-FINAL-2118: Painless contractures

of fingers in a female child. Pediatric Rheumatology 2013 11(Suppl 2):P130. 